\title{
Weak Population Structure of Perna Viridis in Indo- Pacific Region based on Nuclear and Mitochondrial DNA Marker
}

\section{Yingying Ye ( $\nabla$ yeyy@zjou.edu.cn )}

Zhejiang Ocean University https://orcid.org/0000-0003-0056-030X

\section{Chengrui Yan}

Zhejiang Ocean University

\section{Ferruccio Maltagliati}

Pisa University

\section{Zeqin Fu}

Zhejiang Ocean University

\section{Baoying Guo}

Zhejiang Ocean University

\section{Kaida Xu}

Zhejiang Ocean University

xiaojun yan

Zhejiang Ocean University

\section{Original Article}

Keywords: Perna viridis, Indo-Pacific region, genetic variation, molecular markers

Posted Date: February 5th, 2021

DOI: https://doi.org/10.21203/rs.3.rs-179065/v1

License: (9) (1) This work is licensed under a Creative Commons Attribution 4.0 International License. Read Full License 


\section{Abstract}

Perna viridis is a mussel commonly distributed along the Asian Indo-Pacific coasts. It is one of the main cultured species of that region. Previous studies focused mostly on the native populations within single countries; with the present study we analyzed the genetic diversity of $P$. viridis in a large study area, spanning from Oman to southern China. Three molecular markers were used, namely portions of the nuclear ITS region, and the mitochondrial COI gene and D-Loop region. The nuclear marker showed moderate levels of genetic diversity (haplotype diversity $h=0.543$ to 0.897 ) and nucleotide diversity $\pi=0.0022$ to 0.0064 ); whereas mitochondrial markers exhibited higher levels of genetic variability ( $h=0.858$ to 0.964 and $\pi=0.0012$ to $0.0079)$. The estimates of inter-sample genetic divergence $\left(F_{\mathrm{ST}}\right)$ and the analysis of molecular variance highlighted that the Thai population is genetically divergent from the others. Our results showed the genetic variation of $P$. viridis at the rim of South China Sea and obtained the genetic basic information of $P$. viridis.

\section{Introduction}

The Asian green-lipped mussel, Perna viridis (Linnaeus, 1758) (Bivalvia, Mytilidae), is distributed along the Asian coasts of the Indo-Pacific region [1]. Furthermore, $P$. viridis is appreciated seafood rich in EPA, DHA and microelement in its soft part in its distributed areas [2]. With shortly breeding culture and comparatively high tolerance to most environmental conditions [3], P. viridis become a major aquaculture species in many Asian countries $[4,5]$. The life cycle of $P$. viridis sustained one year from the larva to the sexual mature individual. The spawning period is from April to November and the pelagic larvae stage lasts about 17 to 25 days [6]. In this period, the ocean currents in the South China Sea are active potentially promoting $P$. viridis larval dispersal.

In a previous genetic study using 19 microsatellite loci, carried out in samples collected from ten locations of peninsular Malaysia, Ong et al. [7] found a general picture of genetic homogeneity within the study area. Similar results were found in the Gulf of Thailand by Prakoon et al. [5] using five microsatellite loci. Even comparing three natural samples with two cultured populations of $P$. viridis by using nine microsatellite loci, no significant genetic divergence was observed [1]. In China, Ye et al. [8] and Ye et al. [9] also found that the genetic differentiation of the populations of $P$. viridis was non-significant and low based on the mitochondrial DNA and microsatellite markers. It was difficult to investigate whether the local samples were affected by other countries or regions in the South China Sea and showed a non-significant divergence. However, most previous reports of the genetic characterization of $P$. viridis focused on the relationship between location samples in a restricted study area. None of report studied the individuals of $P$. viridis between different sea areas at the rim of South China Sea. The genetic relationship and population structure of different $P$. viridis populations are ambiguity among the natural habitat in the vast South China Sea.

In this study, portions of one nuclear DNA marker (internal transcribed spacers, ITS region) and two mitochondrial DNA markers (Cytochrome C oxidase subunit I, COI; mitochondrion control region, D-Loop region) were employed to investigate the genetic diversity of $P$. viridis in an area spanning from Arabian Sea to South China Sea. With high variable region and easily sequenced, these markers were reliable and common tools for studying genetic diversity and evolution in most species and widely used in mollusk species to estimate interand intra-populations genetic variability [10-12].. Thus, it was beneficial to use different markers for revealing the genetic diversity and genetic structure between different location samples. We explored whether the genetic differentiation of $P$. viridis were similar at the rim of South China Sea. As a reference, several individuals from 
Oman also were tested to compare with the results of $P$. viridis in the East Asia and Southeast Asia. We expected the study could reveal the genetic relationship of wild samples of $P$. viridis at the rim of South China Sea and provide materials of $P$. viridis for the fisheries management.

\section{Material And Methods}

\section{Sample collections and DNA extraction}

Six samples of Perna viridis were collected in Zhangzhou (ZZ), Zhuhai (ZH), Zhanjiang (ZJ), Beihai (BH), in the South China Sea; Suratthani (ST) in the Gulf of Thailand; and Muscat (MC) in Arabian Sea (Table 1 and Fig. 1). The adductor muscle was removed from each individual, fixed in absolute ethanol and stored at $-20^{\circ} \mathrm{C}$ until DNA extraction.

Table 1

Sample details and genetics parameters of Perna viridis from six sampling sites

\begin{tabular}{|c|c|c|c|c|c|c|c|c|c|c|}
\hline \multirow[t]{2}{*}{ Samples } & \multirow{2}{*}{$\begin{array}{l}\text { Sampling } \\
\text { Dates }\end{array}$} & \multirow{2}{*}{$\begin{array}{l}\text { Geographic } \\
\text { coordinates }\end{array}$} & \multicolumn{4}{|l|}{ ITS } & \multicolumn{4}{|c|}{ COI \& D-Loop } \\
\hline & & & $N$ & $n$ & $h$ & $\pi$ & $N$ & $n$ & $h$ & $\pi$ \\
\hline $\mathrm{ZZ}$ & $\begin{array}{l}\text { May } \\
2014\end{array}$ & $\begin{array}{l}23^{\circ} 50^{\prime} \mathrm{N} \\
117^{\circ} 56^{\prime} \mathrm{E}\end{array}$ & 23 & 13 & $\begin{array}{l}0.897 \\
\pm \\
0.045\end{array}$ & $\begin{array}{l}0.0064 \\
\pm \\
0.0022\end{array}$ & 31 & 19 & $\begin{array}{l}0.940 \\
\pm \\
0.029\end{array}$ & $\begin{array}{l}0.0068 \\
\pm \\
0.0006\end{array}$ \\
\hline $\mathrm{ZH}$ & Apr. 2014 & $\begin{array}{l}21^{\circ} 50^{\prime} \mathrm{N} \\
113^{\circ} 56^{\prime} \mathrm{E}\end{array}$ & 24 & 7 & $\begin{array}{l}0.652 \\
\pm \\
0.103\end{array}$ & $\begin{array}{l}0.0038 \\
\pm \\
0.0018\end{array}$ & 27 & 15 & $\begin{array}{l}0.943 \\
\pm \\
0.023\end{array}$ & $\begin{array}{l}0.0068 \\
\pm \\
0.0009\end{array}$ \\
\hline $\mathrm{BH}$ & $\begin{array}{l}\text { Mar. } \\
2014\end{array}$ & $\begin{array}{l}20^{\circ} 50^{\prime} \mathrm{N} \\
109^{\circ} 56^{\prime} \mathrm{E}\end{array}$ & 24 & 6 & $\begin{array}{l}0.543 \\
\pm \\
0.111\end{array}$ & $\begin{array}{l}0.0061 \\
\pm \\
0.0046\end{array}$ & 23 & 17 & $\begin{array}{l}0.949 \\
\pm \\
0.026\end{array}$ & $\begin{array}{l}0.0073 \\
\pm \\
0.0074\end{array}$ \\
\hline ZJ & $\begin{array}{l}\text { Mar. } \\
2014\end{array}$ & $\begin{array}{l}21^{\circ} 50^{\prime} \mathrm{N} \\
108^{\circ} 56^{\prime} \mathrm{E}\end{array}$ & 20 & 9 & $\begin{array}{l}0.853 \\
\pm \\
0.053\end{array}$ & $\begin{array}{l}0.0022 \\
\pm \\
0.0004\end{array}$ & 30 & 18 & $\begin{array}{l}0.949 \\
\pm \\
0.020\end{array}$ & $\begin{array}{l}0.0075 \\
\pm \\
0.0005\end{array}$ \\
\hline ST & Oct. 2015 & $\begin{array}{l}9^{\circ} 12^{\prime} \mathrm{N} \\
99^{\circ} 25^{\prime} \mathrm{E}\end{array}$ & 31 & 6 & $\begin{array}{l}0.643 \\
\pm \\
0.064\end{array}$ & $\begin{array}{l}0.0036 \\
\pm \\
0.0020\end{array}$ & 26 & 12 & $\begin{array}{l}0.858 \\
\pm \\
0.047\end{array}$ & $\begin{array}{l}0.0027 \\
\pm \\
0.0024\end{array}$ \\
\hline $\mathrm{MC}$ & $\begin{array}{l}\text { Feb. } \\
2016\end{array}$ & $\begin{array}{l}23^{\circ} 37^{\prime} \mathrm{N} \\
58^{\circ} 31^{\prime} \mathrm{E}\end{array}$ & 10 & 5 & $\begin{array}{l}0.867 \\
\pm \\
0.071\end{array}$ & $\begin{array}{l}0.0027 \\
\pm \\
0.0004\end{array}$ & 10 & 6 & $\begin{array}{l}0.867 \\
\pm \\
0.120\end{array}$ & $\begin{array}{l}0.0012 \\
\pm \\
0.0002\end{array}$ \\
\hline Total & & & 132 & 30 & $\begin{array}{l}0.789 \\
\pm \\
0.031\end{array}$ & $\begin{array}{l}0.0046 \\
\pm \\
0.0011\end{array}$ & 147 & 48 & $\begin{array}{l}0.957 \\
\pm \\
0.006\end{array}$ & $\begin{array}{l}0.0074 \\
\pm \\
0.0017\end{array}$ \\
\hline
\end{tabular}

The improved salting-out method was employed to extract genomic DNA [13]. After extraction, DNA quality was assessed using $2 \%$ agarose gels electrophoresis with Super Stain (Cwbiotech Co. Ltd., Peking, China). With the NanoDrop 2000 Spectrophotometer (Thermo Scientific), DNA concentration was evaluated by absorption at $260 / 280 \mathrm{~nm}$. DNA was diluted to a final concentration of $50-60 \mathrm{ng} / \mu \mathrm{l}$ and stored at $-20^{\circ} \mathrm{C}$ for further analysis. 


\section{Sequencing}

The sequences of ITS region were obtained by using primers ITS5 (5'-GCATCGATGAAGAACGCAGC-3') and ITS28 (5'-GGAATTCTCCTCCGCTTATTGATATGC-3') [14, 15]. Polymerase chain reaction (PCR) was performed in a $25 \mu \mathrm{l}$ volumes reaction, containing 30-40 ng of template DNA, 4 pmol of each primer, $10 \mu \mathrm{l}$ CW0716 $2 \times$ Taq MasterMix (Cwbiotech. Co. Ltd., Peking, China). Reactions conditions were as follows: after an initial denaturation at $95^{\circ} \mathrm{C}$ for $3 \mathrm{~min}$, then 30 cycles were followed at $95^{\circ} \mathrm{C}$ for $30 \mathrm{~s}, 51^{\circ} \mathrm{C}$ for $30 \mathrm{~s}$ and $72^{\circ} \mathrm{C}$ for $1 \mathrm{~min}$ $30 \mathrm{~s}$, and final elongation at $72^{\circ} \mathrm{C}$ for 10 min in Applied Biosystems Veriti $96-$ Well Thermal Cycler (Applied Biosystems, Inc., Foster City, CA, USA).

Using the software Primer-premer v6, the sequences of COI gene (partly) and D-Loop primers were designed by the PV-F: 5'-TAACGAGGAAGATGCTGTG-3' and PV-R: 5'- TGAGGAATTGAACGGAGAAT-3' based on the complete mitochondrion of $P$. viridis (GenBank: JQ970425). Each PCR was carried out in $25 \mu$ l volumes reaction, including

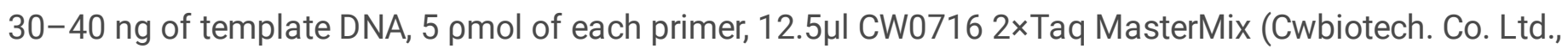
Peking, China). Reactions were performed in $95^{\circ} \mathrm{C}$ for $3 \mathrm{~min}$, then 30 cycles were followed at $95^{\circ} \mathrm{C}$ for $30 \mathrm{~s}, 52^{\circ} \mathrm{C}$ for $30 \mathrm{~s}$ and $72^{\circ} \mathrm{C}$ for $2 \mathrm{~min}$, and final elongation at $72^{\circ} \mathrm{C}$ for $10 \mathrm{~min}$ in Applied Biosystems Veriti $96-$ Well Thermal Cycler (Applied Biosystems, Inc., Foster City, CA, USA).

All the PCR products were tested in the electrophoresis on $1.5 \%$ agarose gels. Then all of them were sent to the sequencing company to bi-directional sequence (BGI Tech Solutions Co., Ltd., shanghai, China).

\section{Data analysis}

The software ClustalX v2.0 [16] was used to align the DNA fragments. Each fragment was compared with complete genome of $P$. viridis online (https://www.ncbi.nlm.nih.gov/) to verify the species and the fragment position.

The sequences of ITS, COI and D-Loop were performed the tests as followed (COI gene and D-Loop region were subsequently concatenated and investigated to consider). Haplotypes were distinguished using the program DnaSP v6.0 and this program was also used to group the specimens and estimate the genetic parameters [17]. To estimate the optimal nucleotide substitution model, the software jModelTest v2 was used to perform the model test [18]. Six samples were divided into 3 groups based on the sample locations (Group1 (China): ZZ, ZH, $\mathrm{BH}$ and ZJ; Group2 (Thailand): ST; Group3 (Oman): MC) and used the program Arlequin v3.5 to estimate the $F_{\mathrm{ST}}$ and perform the analysis of molecular variance [19] with 10,000 permutations. The formula $F_{\mathrm{ST}}=1 /(4 \mathrm{Nm}+1)$ was utilized to calculate the $\mathrm{Nm}$ (Effective number of migrants per generation) [20]. The program MrBayes was used to construct the Bayesian tree of the haplotypes [21]. The program Phylip was used to plot the ML tree of the haplotypes [22]. The heatmap of pairwise $F_{\mathrm{ST}}$ values, $N m$ and UPGMA tree were drawn in R package ggplot2. Ramos-Onsins \& Rozas (2002) [23] $R_{2}$ and $\mathrm{Fu}$ (1997) [24] Fs values were calculated with the program DnaSP v6.0 [17]. The Mantel test (10,000 randomizations) to test for the presence of isolation by distance (IBD) was performed on the matrices of pairwise $F_{\mathrm{ST}}$-values and geographical distances (coastline distance in Log) using R packages abe4. A median-joining network of haplotypes was built using the program Network v. 4.6.1.0 [25]. To analyse the occurrence of genetic structuring, we used the software BAPS v6.0 [26-28]. This program was able to detect panmictic clusters of genetically similar individuals. BAPS was set with six replicate runs for 
each value of $k$ (the maximum number of genetic cluster) up to $k=20$. In addition, we set several reference individuals $n=200$ and repeated the admixture analysis 20 times for individual.

The software DnaSP v. 6.0 was used to obtain mismatch distribution of mitochondrial DNA genes and constructed the plot of mismatch distribution by R packages ggplot2. The parameter of population expansion

$(\tau)$ was estimated by the general non-linear least-square method and the confidence interval was calculated by the parametric bootstrap approach method [29]. The formula $t=\tau / 2 \mu \mathrm{k}(\mathrm{k}$. the length of the sequence; $\mu$. the mutation rate of the gene) was used to estimate the actual expansion time $(t)$. The generation time was one year for the $P$. viridis. Due to lack of specific record in green-lipped mussel fossil and the molecular clock of different makers was different, in this study, $1 \%$ 2\%/Ma was chosen as evolution rate to calculate a conservative time range of expansion [15].

\section{Results}

\section{Genetic diversity analysis}

There are 132 sequences were aligned and classified. A total of $735 \mathrm{bp}$ length of fragment consisted of $18 \mathrm{~S}$ rRNA (partial), ITS region (ITS1, 5.8S rRNA and ITS2) and 28S rRNA (partial) gene of each sequence. Total of 30 unique haplotypes was distinguished (GenBank accession number: MH279793-MH279822). The sample size $(\mathrm{M})$ ranged from $10(\mathrm{MC})$ to $31(\mathrm{ST})$. The number of haplotypes $(n)$ ranged from $5(\mathrm{MC})$ to $13(\mathrm{ZZ})$. Haplotype and nucleotide diversity $(h \& \pi)$ varied from $0.543(\mathrm{BH})$ to $0.897(\mathrm{ZZ})$, averaged of 0.789 and $0.0022(\mathrm{ZJ})$ to 0.0064 (ZZ), averaged of 0.0046 respectively. Haplotype number per population ranged from 5 (MC) to 13 (ZZ). Hap1 was the main haplotype accounting for $41.67 \%$ with 55 individuals (Fig. 2). Most individuals were gathered in Hap1, Hap2 and Hap25. Other haplotypes appeared in few or single individuals. Using the optimal model (GTR + I model), $12.80 \%$ of variation was attributed among populations and $3.20 \%$ of variation was among populations within groups. Apart from that, the genetic difference within populations explained $84.00 \%$ of the total variation (Table 2). In $\Phi$ - statistics, $\Phi_{C T}=0.128(P>0.05), \Phi_{S C}=0.037(P<0.05), \Phi_{S T}=0.160(P<$ 0.05). This result suggested lacking adequate genetic exchange within populations would cause the divergence between three groups and the influence of genetic divergence was resulted by inter-populations no inter-groups. 
Table 2

AMOVA for Six populations of Perna viridis using the software Arlequin 3.5.1

\begin{tabular}{|c|c|c|c|c|c|c|}
\hline Gene & Source of variation & d.f. & $\begin{array}{l}\text { Sum of } \\
\text { Squares }\end{array}$ & $\begin{array}{l}\% \text { of } \\
\text { variation }\end{array}$ & $\begin{array}{l}\Phi- \\
\text { statistics }\end{array}$ & $\begin{array}{l}P \text { - } \\
\text { values }\end{array}$ \\
\hline \multirow[t]{3}{*}{ ITS } & Among groups & 2 & 4.518 & 12.80 & $\begin{array}{l}\Phi_{C T}= \\
0.128\end{array}$ & 0.067 \\
\hline & $\begin{array}{l}\text { Among populations within } \\
\text { groups }\end{array}$ & 3 & 1.995 & 3.20 & $\begin{array}{l}\Phi_{S C}= \\
0.037\end{array}$ & 0.036 \\
\hline & Within populations & 126 & 44.586 & 84.00 & $\begin{array}{l}\Phi_{S T}= \\
0.160\end{array}$ & 0.002 \\
\hline \multirow{3}{*}{$\begin{array}{l}\text { COI } \\
\& \\
\text { D- } \\
\text { Loop }\end{array}$} & Among groups & 2 & 3.016 & 6.36 & $\begin{array}{l}\Phi_{C T}= \\
0.064\end{array}$ & 0.040 \\
\hline & $\begin{array}{l}\text { Among populations within } \\
\text { groups }\end{array}$ & 3 & 1.974 & 1.46 & $\begin{array}{l}\Phi_{S C}= \\
0.016\end{array}$ & 0.026 \\
\hline & Within populations & 141 & 64.473 & 92.17 & $\begin{array}{l}\Phi_{S T}= \\
0.078\end{array}$ & 0.001 \\
\hline
\end{tabular}

There are 558bp of COI partial fragments and 660bp of D-Loop partial fragments were obtained. COI and DLoop sequences were subsequently concatenated (1218bp, GenBank accession number: MH285339$\mathrm{MH} 285378) .147$ sequences were aligned, and 40 unique haplotypes were obtained. The samples size $(M)$ ranged from $10(\mathrm{MC})$ to 31 (ZZ). The number of haplotypes $(n)$ ranged from $4(\mathrm{MC})$ to $18(\mathrm{ZZ})$. The haplotypes diversity $(h)$ and nucleotide diversity $(\pi)$ varied from $0.858(\mathrm{ST})$ to $0.964(\mathrm{BH})$ with an average of 0.957 and 0.0012 (MC) to 0.0079 (ZJ) with an average of 0.0074 . Hap1 was the maximum haplotype accounting for $12.24 \%$ with 18 individuals (Fig. 2). About $6.36 \%$ of variation was attributed among populations and $1.46 \%$ was within populations by the AMOVA based on the $\mathrm{JC}$ model. Apart from that, the genetic difference within populations explained $92.17 \%$ of the total variation (Table 2). For the $\Phi$ - statistics, $\Phi_{C T}=0.064(P<0.05), \Phi_{S C}=$ $0.016(P<0.05), \Phi_{S T}=0.078(P<0.05)$. This result was consistent with the result of ITS region analysis. The genetic divergence was mainly caused by inter-populations.

\section{Population Structure Analysis}

Pairwise $F_{\mathrm{ST}}$ values of ITS region (ranged from -0.022 to 0.242 , the heatmap of $F_{\mathrm{ST}}$ values and the $P$ values were showed in Fig. 3) suggested a negligible genetic divergence among four samples (ZZ, ZH, BH, ZJ) and populations of ST and MC were obviously difference with other four populations. The plot of haplotypes network showed the similar evidence that frequent genetics exchange among six populations. These results in several same haplotypes would be detected in most individuals. When $K=2$ (Fig. 4), the populations of ST and $\mathrm{MC}$ were the first to be isolated from other four populations. It indicated that except ST and MC, other populations had profundity genetics exchanged. If populations of ST and MC cluster as a group, the other four populations would be another group. The clustering result indicated that the genetic exchange existed within populations among groups and no or little genetic exchange occurred between groups. 
Pairwise $F_{S T}$ values of COI \& D-Loop region (ranged from 0.009 to 0.200 , the heatmap of $F_{\mathrm{ST}}$ values and the $P$ values were showed in Fig. 3) indicated that a genetic divergence within six populations and samples from Muscat were obviously divergence with others. In the plot of haplotypes network, all haplotypes were clustered into two parts and there was a difference between samples from Muscat and Suratthani (Fig. 2). Haplotypes structure of MC was different from that of the samples of China and Thailand, which means that population of MC lacked genetic exchange with others. Based on the Bayesian clustering method to simulate and evaluate genetic structure, when $K=2$ (Fig. 4), MC was the first site isolated from other sites. It supported that except MC, other populations had widely genetics exchanges among them and population of $\mathrm{MC}$ limited genetics exchange with other populations. Therefore, the best $K$ value supported two clusters were the most reliable clustering in the population structure.

\section{Evolution And Dynamics Analysis}

Due to the non-coding region of ITS region and D-Loop region, sequence of COI was selected to analysis the expansion. The detected $D$ and $F$ values were negative in ST population and the SSD value was non-significant. The plot of mismatch distribution confirmed the model of population expansion (Fig. 5). Thus, it revealed that only the ST population had a recent population expansion (Table 3). Based on the formula $t=\tau / 2 \mu k$, the expansion time was estimated between 0.2 Ma to 0.24 Ma [15].

Table 3

Neutrality test and Goodness-of-fit test of six populations based on COI sequences

\begin{tabular}{|lllllll|}
\hline Populations & \multicolumn{2}{l}{$\boldsymbol{R}_{\mathbf{2}}$ statistic } & Fu's Fs & & \multicolumn{2}{l|}{ Goodness-of-fit test } \\
\cline { 2 - 7 } & $\boldsymbol{R}_{\mathbf{2}}$ & $\boldsymbol{P}$ & Fs & $\boldsymbol{P}$ & SSD & $\boldsymbol{P}$ (Sim,Ssd \\
& & & & & & $\geq$ Obs.Ssd) \\
\hline ZZ & 0.115 & 0.474 & -0.422 & 0.459 & - & - \\
\hline ZH & 0.117 & 0.439 & -0.620 & 0.414 & - & - \\
BH & 0.161 & 0.786 & -0.465 & 0.454 & - & - \\
ZJ & 0.158 & 0.816 & 1.209 & 0.782 & - & - \\
\hline ST & 0.094 & 0.110 & -2.550 & 0.009 & 0.005 & 0.544 \\
\hline MC & - & - & - & - & - & - \\
\hline
\end{tabular}

\section{Discussion}

\section{Genetic diversity within populations}

For ITS region among six populations, the high haplotypes diversity was detected in the populations of $\mathrm{ZZ}, \mathrm{ZJ}$ and $\mathrm{MC}(h>0.85)$. The populations of $\mathrm{ZZ}$ and $\mathrm{BH}$ indicated high nucleotide diversity $(\pi>0.005)$. The highest genetic diversity was observed in ZZ population, where 13 haplotypes were determined. However, the genetic diversity was in a median level for the total of six populations. Except ZZ, the numbers of detection haplotypes 
in other five populations were less than 10 and most of individuals were detected the Hap1. In the plots of network and Bayesian and ML tree of haplotypes of ITS region (Figs. 2 and 6), obvious divergence was not found. There was no evident difference in haplotypes between three countries. There was no discernible divergence between endemic haplotypes. It is evident from the evolutionary tree that haplotypes of six populations were mixed and clustered.

For COI \& D-Loop region among six populations, all populations were estimated high haplotypes diversity $(h>$ $0.85)$. All Chinese populations were found a higher the nucleotide diversity $(\pi>0.007)$ than the populations in Thailand and Oman $(\pi<0.003)$. Overall, the genetic diversity of Chinese populations was different from populations in Thailand or Oman. Chinese populations of $P$. viridis revealed a high-level diversity and had abundant haplotypes (except the shared haplotypes, populations in China had 24 haplotypes, Thailand population had 7 haplotypes and Oman population had 3 haplotypes.). The ratio of detection haplotypes in Chinese population was higher than the populations in Thailand and Oman. For six populations, it was evident that richness of haplotypes in Thailand and Oman were lower than in China. Other than the result of ITS region, no haplotype was detected in most of individuals. Thus, it supported that the genetic diversity of Chinese populations was in a high level. In the plots of haplotype network and Bayesian and ML tree of COI and D-Loop region (Figs. 2 and 6), it was obvious that the population of MC had a divergence with ST. Moreover, it revealed all haplotypes were clustered into two groups.

The extent of intra-specific variability of mtDNA is generally higher in most invertebrates, and it is common to estimate a high-level diversity in mtDNA. Thus, compared with the results of ITS region and COI \& D-Loop region, it can be found that the total genetic diversity in COI \& D-Loop region was higher than that in ITS region and the detection haplotypes in COI \& D-Loop region was also more than that in ITS region. In China South Sea, gulf of Thailand and others tropical coastal areas, with its short growth cycle and high yield, $P$. viridis had a supplement breeding tradition. Due to its short growth cycle, two location-closed populations would have a frequently gene flow, and the frequent genetic exchange narrowed the differences within populations. Therefore, there were fewer differences among four populations in China and higher divergence among populations in different locations.

\section{Genetic Structure Among Populations}

As the similar result of the genetic diversity, the genetic structure showed a distinct divergence. From the plot of pairwise $F_{\mathrm{ST}}$ values and the UPGMA tree, the color of populations of ST and MC were deeper than other four populations in China. It revealed that a genetic divergence existed between three groups. The suitable $K$ value test showed that two region sequences were divided into two groups. According to the data of FAO, $P$. viridis was a popular breeding species in tropical zone. The introduction and interbreeding of $P$. viridis were frequent among the tropical coastal countries. For example, in China, Guangdong province strived to develop the breeding of $P$. viridis since 1991. Since the good breeds of $P$. viridis were selected, the fast-developing coastal aquafarm of $P$. viridis partly promoted the gene exchange within the wild populations in the China South Sea. Otherwise, in the China South Sea, the complex and fast current system also partly promoted the gene exchange among the populations. The $F_{S T}$ values of each microsatellite loci indicated that genetic divergence of each population was 
negligible. Thus, in the mtDNA sequence with relative high-ratio of evolution, if they are geographically closer, the genetic divergence and the $F_{S T}$ values would be lower.

In Thailand, most aquaculture of $P$. viridis stemmed from the same place and with the relative closure of the gulf of Thailand, it possibly caused the different with the populations of China and Oman. The $F_{S T}$ values of ITS region and COI \& D-Loop region also supported that the population of ST was obviously significant divergent from other populations. In a relatively closed gulf, the gamete of $P$. viridis was difficult to exchange with other populations. Similarly, in geographic distance, the population of MC was far away from other populations. The results of COI \& D-Loop region supported that the pairwise $F_{S T}$ values of $\mathrm{MC}$ was significantly different from other populations. However, the result of ITS region was not obvious. Thus, four ITS sequences of other three countries (Vietnam, Philippines and India) were selected to construct the UPGMA tree with all haplotypes and the result revealed that most of the sequences were clustered together. Therefore, in ITS region, most of the habitat of $P$. viridis possibly stemmed from the similar male parent unless there was a relative geographical isolation that limited the communication of male gamete (such as the gulf of Thailand).

\section{Evolution Dynamics}

There was no indication for possible positive selection acting on the mitochondrial COI gene through analyses of the $\mathrm{Ka} / \mathrm{Ks}$ test. Generally, marine animals were subjected to purifying selection and the mitochondrial genes were commonly subjected to the purifying selection to pursue thermoregulation and efficient energy metabolism [30-32]. This result revealed that in the China South Sea, the populations of $P$. viridis possibly lived under pressure of rising ocean temperatures, frequency human activities and others environmental factors.

For the neutrality test, except the lacked data of MC, only the population of ST was negative with no-significant SSD value (Table 3). The mismatch distribution showed that population of ST had a recent population expansion event. However, other populations revealed no recent population expansion events. These results were possibly caused by the reasons as followed. Firstly, for Pleistocene in China South Sea, the relatively rich current system and wide ocean area could ensure the genetic exchange within populations and protect the habitats of $P$. viridis from destruction. Secondly, in the gulf of Thailand, due to a relatively closed environment, the population of $P$. viridis was limited without enough genetic exchange. In Pleistocene, the gulf was isolated with the external environment. Weak population structure could not withstand the environmental change, especially for the sedentary mussels. Last, in Thailand, most aquaculture of $P$. viridis derived from the same place. It was possible that some data of populations in Thailand was not collected. Recently, the globally aquaculture was in fast development. Most countries chose to develop Mollusk for its importance and economic-value species. In this tactic, more improved varieties were introduced and bred. Thus, the mantel tests did not show a significant relation between genetic distance and geographic distance (Fig. 7). These results suggested that the study of genetic diversity and structure of $P$. viridis were possibly developed into two groups and the populations of China were obviously different from the outside populations. The results showed that different between mtDNA and nucleotide DNA was due to genetically different ways of the two DNA that generated slightly different results.

\section{Conclusion}


It was important to analysis the population genetic and structure to obtain the genetic information of $P$. viridis. In this study, the populations of ST and MC were divergence with the populations of China. The difference among populations of China was limited. Therefore, it was good way to introduce the good breed of $P$. viridis in different countries to improve the resilience and yield of the native species.

\section{Declarations}

\section{Conflict of interest}

The authors declare that the research was conducted in the absence of any commercial or financial relationships that could be construed as a potential conflict of interest.

\section{Acknowledgements}

This work was financially supported by the National Key R\&D Program of China(2019YFD0901204), Natural Science Foundation of Zhejiang Province (Grant No.: LQ18D060004), NSFC Projects of International Cooperation and Exchanges (42020104009), National Natural Science Foundation of China (41976111 and 42076119) and the Project of Bureau of Science and Technology of Zhoushan (Funding No.: 2019F12004 and 2020C21026).

\section{References}

1. Lin G, Feng F, Yue GH (2007) Isolation and characterization of polymorphic microsatellites from Asian green mussel (Perna viridis). Mol Ecol Notes 7:1036-1038. https://doi.org/10.1111/j.14718286.2007.01765.x

2. Qing N, Lin Y, Jin Q (2000) Studies on nutritive compositions of soft part in mussel Perna viridis (in Chinese with English abstract). Tropic Oceanology 19:81-84

3. Rajagopal S, Venugopalan VP, Velde GVD et al (2006) Greening of the coasts: a review of the Perna viridis success story. Aquat Ecol 40:273-297. https://doi.org/10.1007/s10452-006-9032-8

4. Rajagopal S, Venugopalan VP, Velde GVD et al (1998) Reproduction, growth rate and culture potential of the green mussel, Perna viridis L in Edaiyur backwaters, east coast of India. Aquaculture 162:187-202

5. Prakoon W, Tunkijjanukij S, Nguyen TTT et al (2010) Spatial and temporal genetic variation of green mussel, Perna viridis in the Gulf of Thailand and implication for aquaculture. Mar Biotechnol 12:506 -506 15. https://doi.org/10.1007/s10126-009-9234-x

6. Wang ZR (1997) Fauna Sinica. Science Press, Beijing (in Chinese)

7. Ong CC, Yusoff K, Yap CK et al (2009) Genetic characterization of Perna viridis $L$ in peninsular Malaysia using microsatellite markers. J Genet 88:153-163. https://doi.org/10.1007/s12041-009-0023-0

8. Prakoon W, Tunkijjanukij S, Nguyen TTT et al (2010) Spatial and temporal genetic variation of green mussel, Perna viridis in the Gulf of Thailand and implication for aquaculture. Mar Biotechnol 12:506 -506 15. https://doi.org/10.1007/s10126-009-9234-x 
9. Ye YY, Li JJ, Wu CW (2015) Genetic diversity and population connectivity of the Asian green mussel Perna viridis in South China Sea, inferred from mitochondria DNA markers. Biochem Syst Ecol 61:470-476. https://doi.org/10.1016/j.bse.2015.07.009

10. Ye YY, Senanan W, Li JJ et al (2016) Genetic diversity and population structure of the Asian green mussel Perna viridis in South China Sea based on microsatellite markers. Biochem Syst Ecol 68:135-141. https://doi.org/10.1016/j.bse.2016.07.010

11. Chu KH, Li CP, Ho HY (2001) The first internal transcribed spacer (ITS-1) of ribosomal DNA as a molecular marker for phylogenetic and population analyses in crustacea. Mar Biotechnol (NY) 3:355 -3:355 61.https://doi.org/10.1007/s10126001-0014-5

12. Chao Z, Liao J, Liang Z et al (2014) Cytochrome $C$ oxidase subunit I barcodes provide an efficient tool for Jinqian Baihua She (Bungarus parvus) authentication. Pharmacogn Mag 10:449 -449 57. https://doi.org/10.4103/0973-1296.141816

13. Shi F, Xiong MH, Zheng HT et al (2018) Genetic Structure Analysis of Three Pseudogyrincheilus procheilus Populations in the Yangtze River Basin. Journal of Hydroecology 39:58-63

14. Aljanabi SM, Martinez I (1997) Universal and rapid salt-extraction of high quality genomic DNA for PCRbased techniques. Nucleic Acids Res 25:4692-4693. https://doi.org/10.1093/nar/25.22.4692

15. Wagstaff SJ, Garnock-jones PJ (1998) Evolution and biogeography of the Hebecomplex (Scrophulariaceae) inferred from ITS sequences. NZ J Bot 36:425-437. https://doi.org/10.1080/0028825x.1998.9512581

16. Wood AR, Apte S, Macavoy ES et al (2007) A molecular phylogeny of the marine mussel genus Perna (Bivalvia: Mytilidae) based on nuclear (ITS1\&2) and mitochondrial (COI) DNA sequences. Mol Phylogenet Evol 44:685 -685 98. https://doi.org/10.1016/j.ympev.2006.12.019

17. Larkin MA, Blackshields G, Brown NP et al (2007) Clustal W and Clustal X version 20. Bioinformatics 23:2947-2948

18. Rozas J, Ferrer-mata A, Sánchez-delbarrio JC et al (2017) DnaSP 6: DNA Sequence Polymorphism Analysis of Large Data Sets. Mol Biol Evol 34:3299-3302.https://doi.org/10.1093/molbev/msx248

19. Posada D (2008) jModelTest: phylogenetic model averaging. Molecular Biology Evolution 25:1253-1256. https://doi.org/10.1093/molbev/msn083

20. Excoffier L, Lischer H (2010) Arlequin suite ver 35: a new series of programs to perform population genetics analyses under Linux and Windows. Mol Ecol Resour 10:564-567. https://doi.org/10.1111/j.17550998.2010.02847.x

21. Frankham R (2010) Introduction to conservation genetics, 2nd ed, Cambridge University Press.https://doi.org/10.1007/978-1-4757-2504-9_1

22. Huelsenbeck JP, Ronquist F (2001) MRBAYES: Bayesian inference of phylogenetic trees. Bioinformatics 17:754-755. .https://doi.org/10.1093/bioinformatics/17.8.754

23. Felsenstein J (1996) PHYLIP:Phylogeny inference package. Version 3572. https://doi.org/10.1002/9780471650126.dob0534.pub2

24. Ramos-onsins SE, Rozas J (2002) Statistical properties of new neutrality tests against population growth. Mol Biol Evol 19:2092 -2092 100. https://doi.org/10.1093/molbev/msl052

25. Fu YX (1997) Statistical Tests of Neutrality of Mutations Against Population Growth, Hitchhiking and Background Selection. Genetics 147:915-925

Page $11 / 17$ 
26. Bandelt HJ, Forster P, Rohl A (1999) Median-joining networks for inferring intraspecific phylogenies. Mol Biol Evol 16:37-48. https://doi.org/10.1093/oxfordjournals.molbev.a026036

27. Corander J, Waldmann P, Sillanpää MJ (2003) Bayesian analysis of genetic differentiation between populations. Genetics 163:367-374

28. Corander J, Marttinen P (2006) Bayesian identification of admixture events using multilocus molecular markers. Mol Ecol 15:2833-2843. https://doi.org/10.1111/j.1365-294x.2006.02994.x

29. Cheng L, Connor TR, Sirén J et al (2013) Hierarchical and Spatially Explicit Clustering of DNA Sequences with BAPS Software. Molecular Biology Evolution 30:1224. https://doi.org/10.1093/molbev/mst028

30. Schneider S, Excoffier L (1999) Estimation of Past Demographic Parameters From the Distribution of Pairwise Differences When the Mutation Rates Vary Among Sites: Application to Human Mitochondrial DNA. Genetics 152:1079-1089

31. Shearer TL, Oppen MHV, Romano SL et al (2002) Slow mitochondrial DNA sequence evolution in the Anthozoa (Cnidaria). Mol Ecol 11:2475-2487. https://doi.org/10.1046/j.1365-294x.2002.01652.x

32. Duran S, Palacin C, Becerro MA et al (2004) Genetic diversity and population structure of the commercially harvested sea urchin Paracentrotus lividus (Echinodermata, Echinoidea). Mol Ecol 13:3317-3328. https://doi.org/10.1111/j.1365-294x.2004.02338.x

33. Roman J, Palumbi SR (2004) A global invader at home: population structure of the green crab, Carcinus maenas, in Europe. Mol Ecol 13:2891-2898. https://doi.org/10.1111/j.1365-294x.2004.02255.x

\section{Figures}




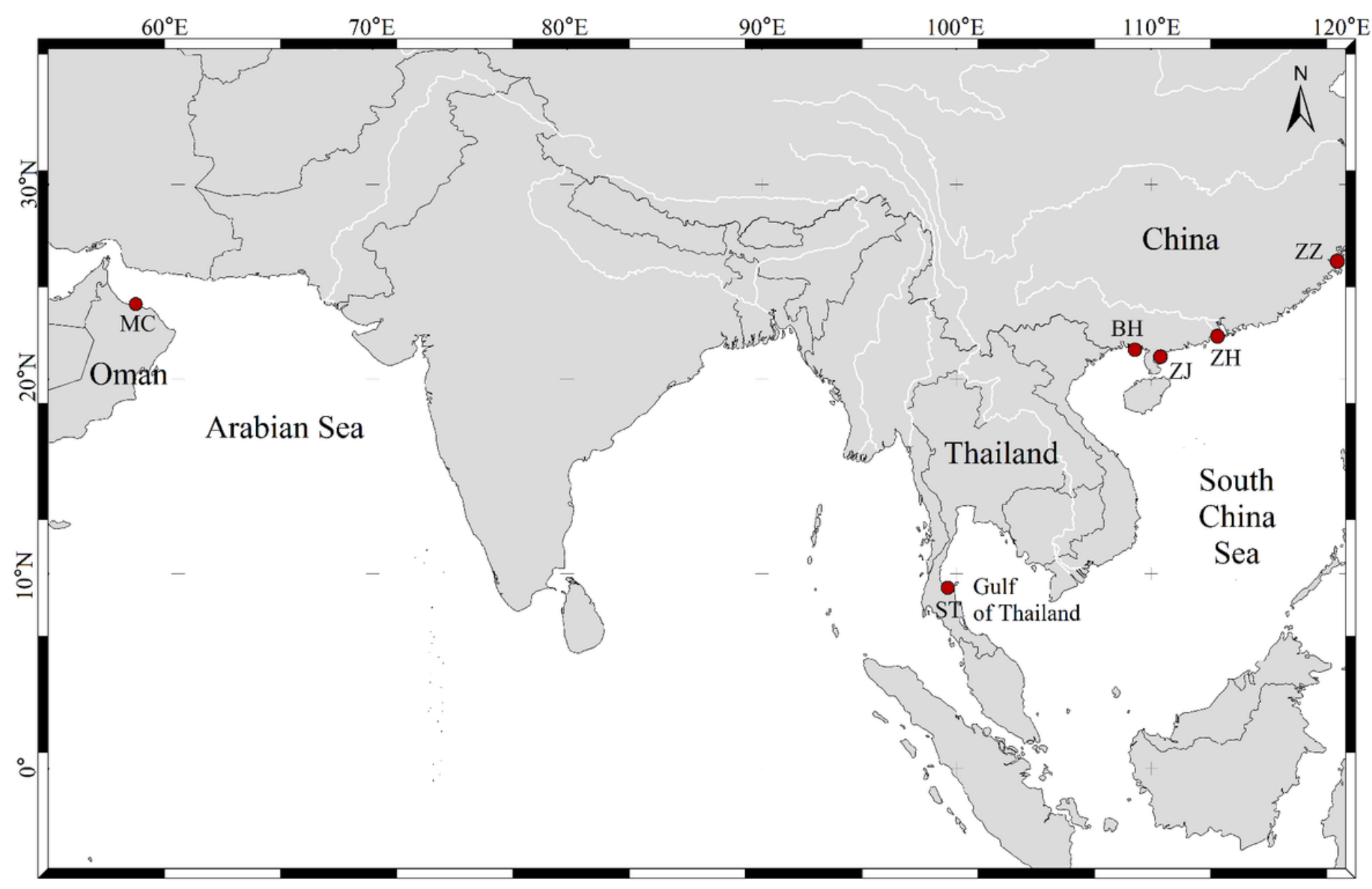

Figure 1

The map of sampling details for six samples of P.viridis Note: The designations employed and the presentation of the material on this map do not imply the expression of any opinion whatsoever on the part of Research Square concerning the legal status of any country, territory, city or area or of its authorities, or concerning the delimitation of its frontiers or boundaries. This map has been provided by the authors.
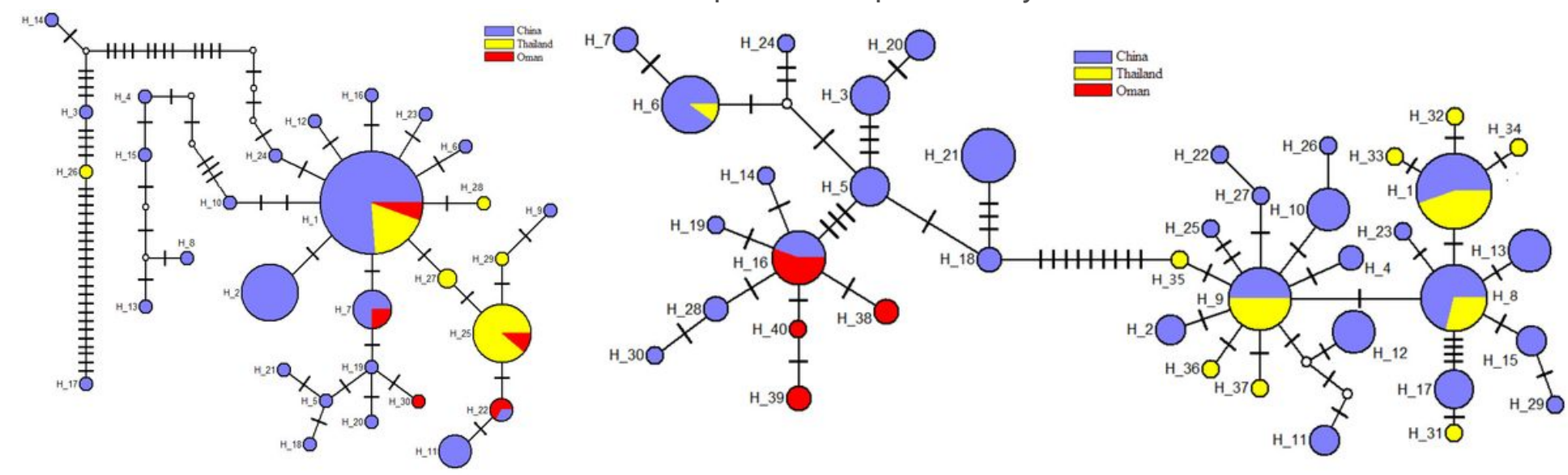

\section{Figure 2}

The plot of haplotypes network based on ITS and COI \& D-Loop regions 


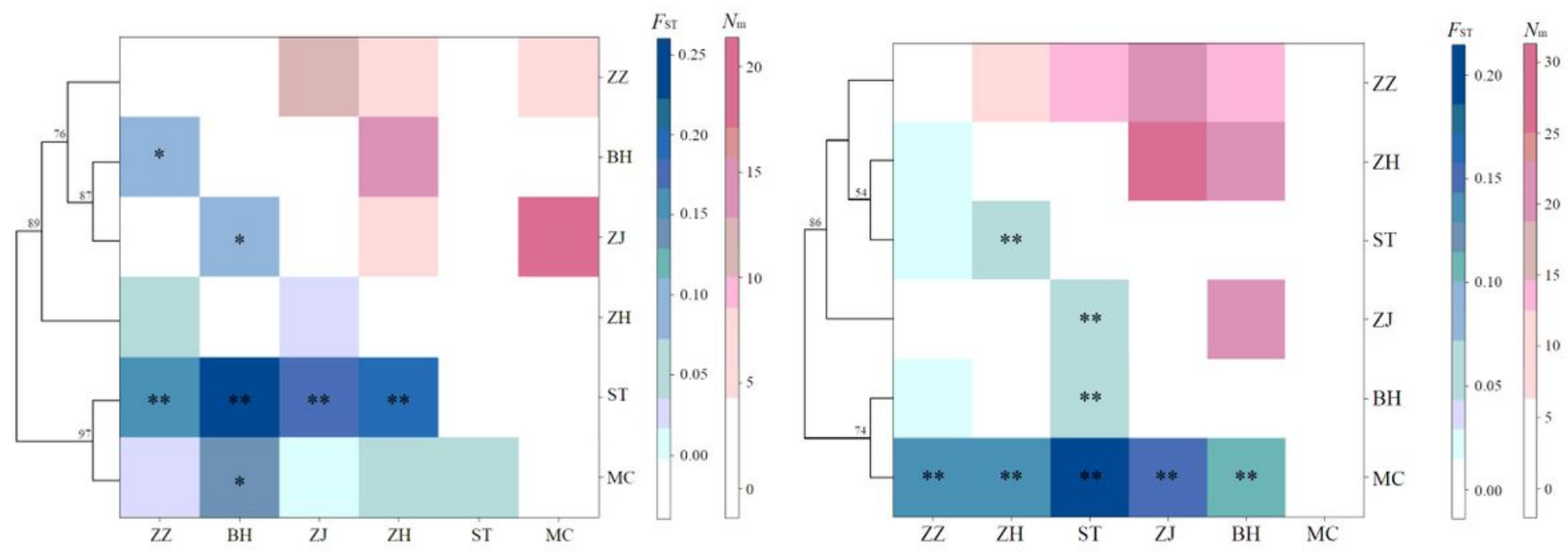

Figure 3

The heatmap of FST and Nm based on ITS and COI \& D-Loop regions with the UPGMA tree $(* P<0.05 ; * \star P<$ 0.01)

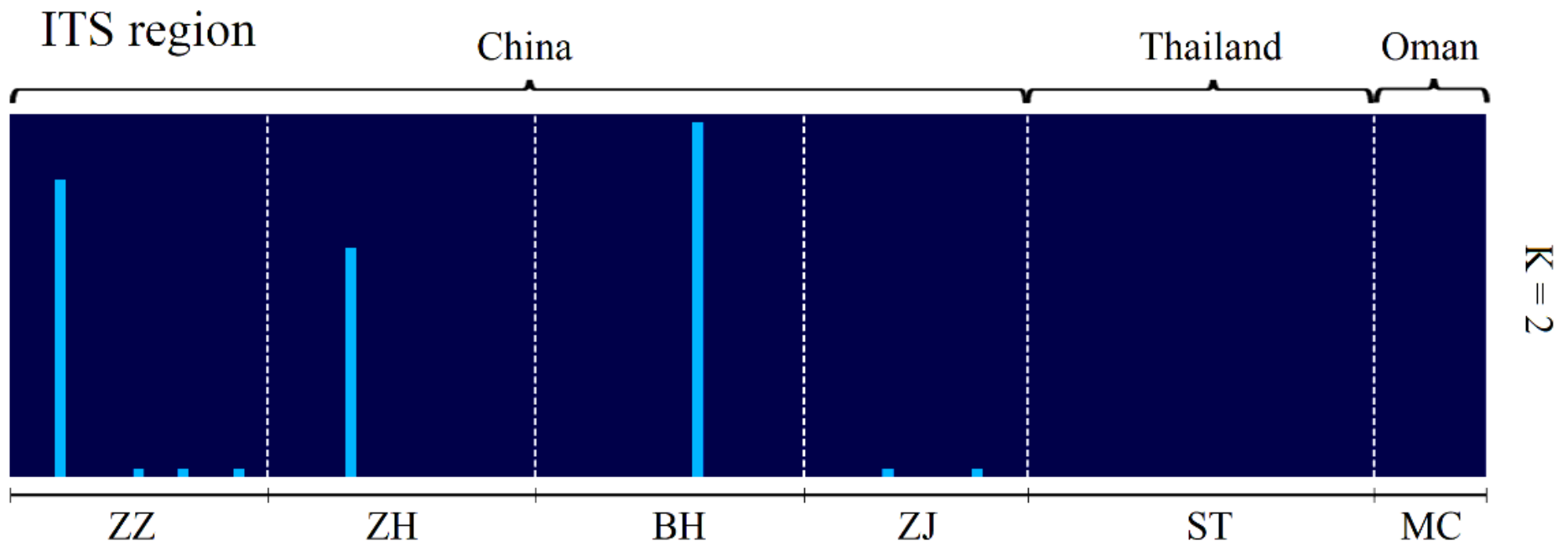

COI \& D-Loop region China

Thailand Oman

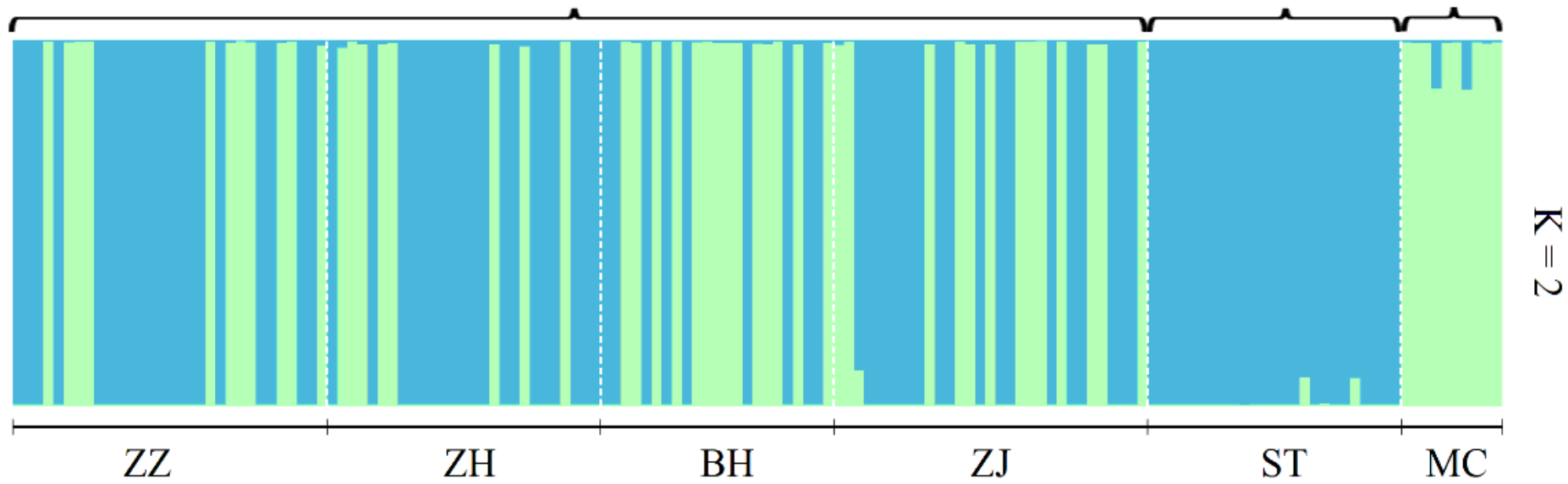


Figure 4

STRUCTURE analysis based on the ITS region sequence and the COI \& D-Loop region sequence.

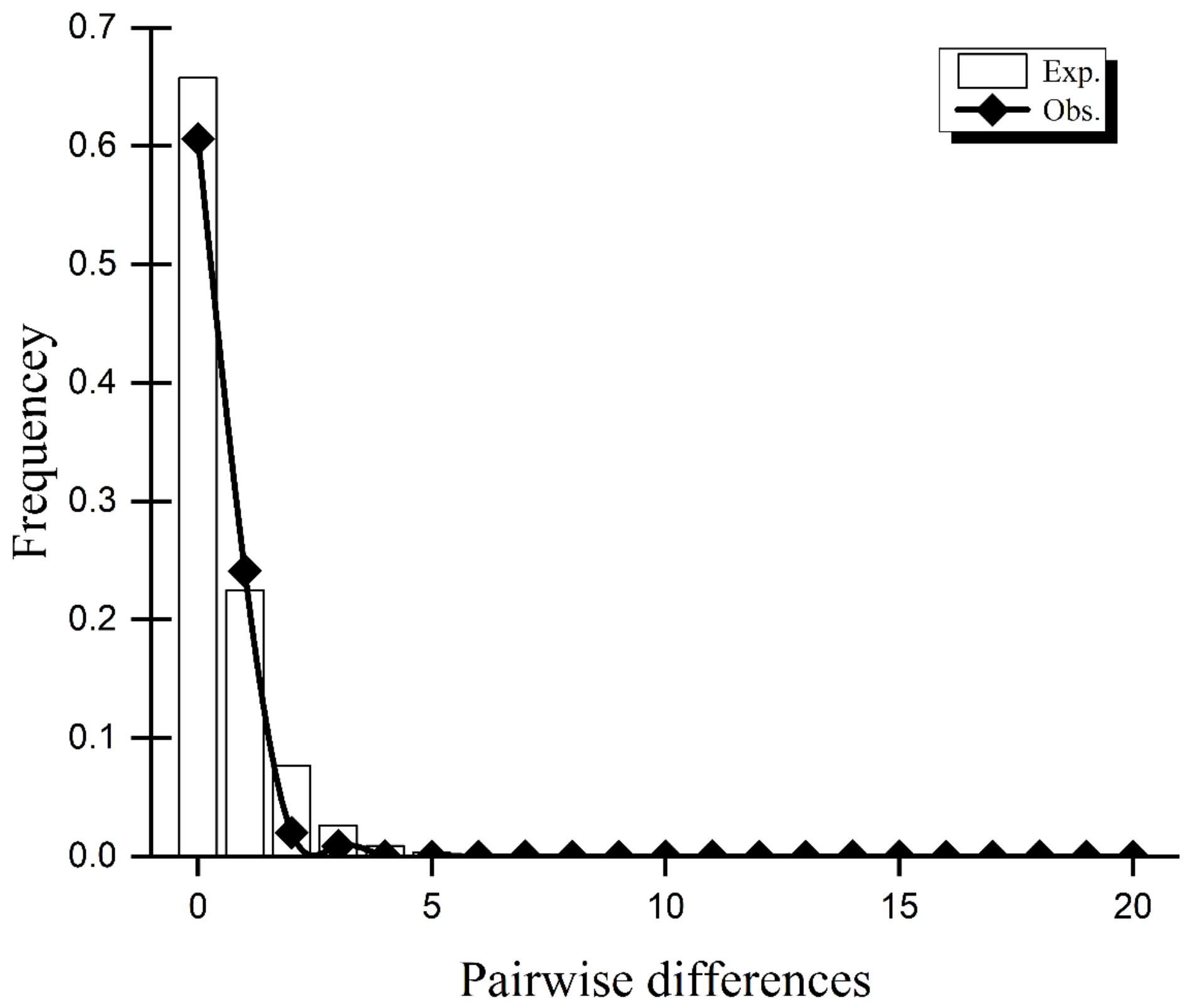

Figure 5

The plot of mismatch distribution for ST population based on the mitochondrial DNA sequence using the DnaSP program. 
ITS

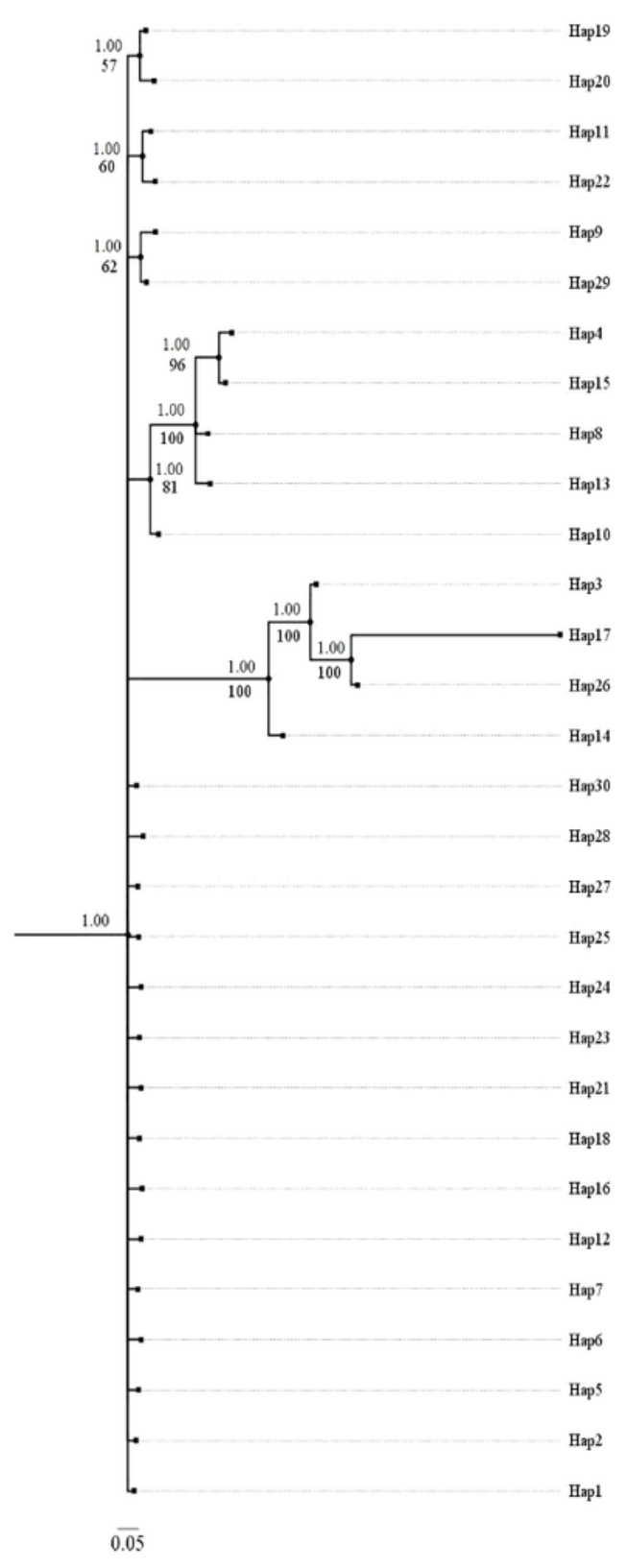

\section{COI \& D-Loop}

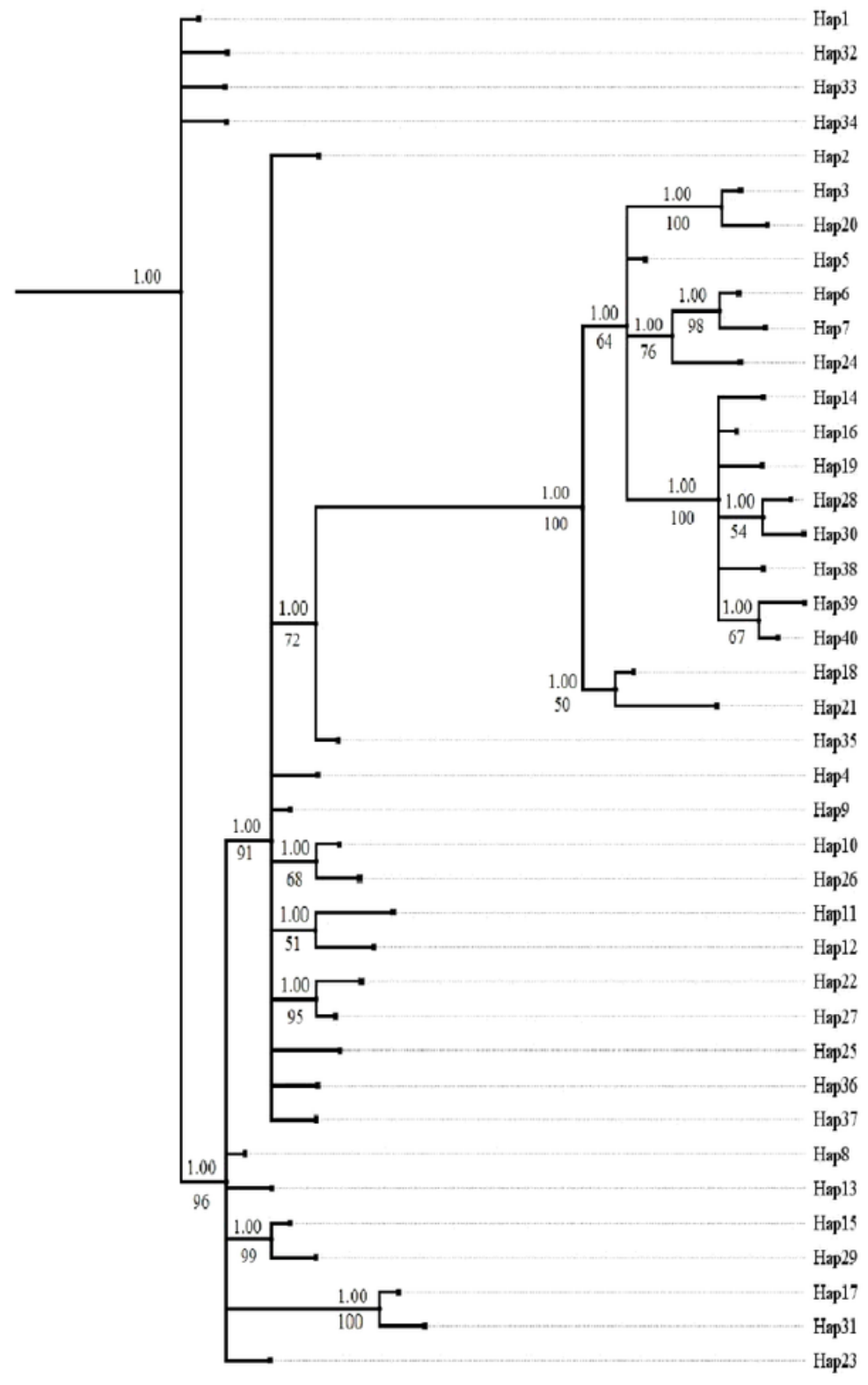

$\overline{0.001}$

Figure 6

The Bayesian and ML trees of ITS region and COI \& D-Loop region using the MrBayes and Phylip. 

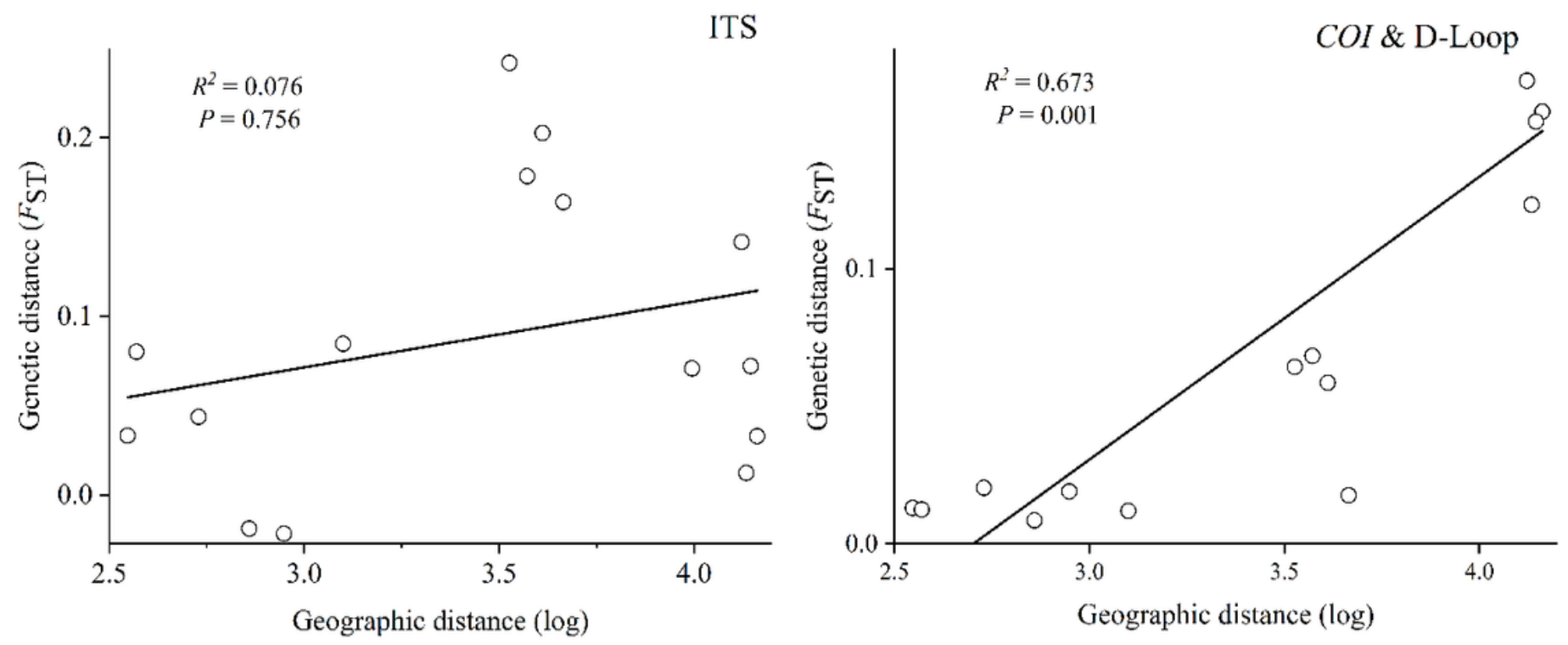

Figure 7

The plots of mantel test for ITS and COI \& D-Loop region 